\title{
Perspectivas emergentes en el arte cerámico. Análisis de la obra de Rafa Pérez y Gregorio Peño
}

\author{
María Florencia Serra, Agustina Paltrinieri y Nicolás Rendtorff \\ Facultad de Artes, Universidad Nacional de La Plata (FdA- UNLP); Centro de Tecnología de Recursos Minerales y Cerámica (CETMIC) \\ y Consejo Nacional de Investigaciones Científicas y Técnicas (CONICET) \\ serramariaflorencia@hotmail.com; aguspaltrinieri@yahoo.com.ar; rendtorff@cetmic.unlp.edu.ar
}

RESUMEN: Al ser una práctica milenaria, el arte cerámico cuenta con un legado histórico que reúne saberes, modos de hacer y concepciones tradicionales. Como toda trayectoria histórica presenta continuidades y rupturas en sus permanentes actualizaciones. El presente trabajo analiza el surgimiento de una estética del arte cerámico actual que propone desplazamientos respecto a la relación sujeto-materia y una revisión de los modos de concebir la materialidad cerámica. Para ello analizaremos las propuestas artísticas de dos consagrados ceramistas contemporáneos: Rafa Pérez y Gregorio Peño. Atenderemos la articulación entre los procesos constructivos, los resultados formales y algunos pronunciamientos de los artistas que nos permitan reconocer sus posicionamientos. De este análisis se desprende que los comportamientos de la materia, sus reacciones y contingencia, cobran un rol protagónico en estas propuestas artísticas. Reconocemos allí la resonancia de estas nuevas tendencias que nos permiten delinear un giro materialista en el arte cerámico.

PALABRAS CLAVE: Arte cerámico; Materialidad; Potencia de actuar; Morfogénesis.

\section{Emerging Perspectives in Ceramic Art. Analysis of Work by Rafa Pérez and Gregorio Peño}

ABSTRACT: Being an ancient practice, ceramic art has a historical legacy that brings together traditional knowledge. As with any historical trajectory, it presents continuities and ruptures in its permanent updates. This article analyzes the emergence of a current ceramic art aesthetic that proposes displacements concerning the subject-matter relationship and a review of the modes of conceiving ceramic materiality. We will analyze the artistic proposals of two renowned ceramic artists: Rafa Pérez and Gregorio Peño. We will pay attention to the articulation between the construction processes, the formal results and statements by the artists that allow us to acknowledge their position. From this analysis we can deduce that the behavior of the raw. material, its reactions and contingencies, take on a leading role in these artistic proposals. We acknowledge here the resonance of a new materialness that allows us to delineate a material turn in ceramic art.

KEYWORDS: Ceramic Art; Materiality; Power to Act; Morphogenesis.

Recibido: 10 de febrero de 2021 / Aceptado: 4 de junio de 2021.

Introducción

«[...] La materialidad normativa legada por la tradición era respetada y transmitida como un valor absoluto. En cambio, en la época contemporánea se toma conciencia de que es una construcción cultural variable y relativa.»

Carmen Bernárdez Sanchís (2018: 3)

Transitamos una época que busca desnaturalizar algunas concepciones y categorías histórica, social y culturalmente construidas que se presentaban como eternas e inmutables, para reubicar el lugar de lo humano en aquello que pensamos. Para

Cómo citar este artículo: FLORENCIA SERRA, María, PALTRINIERI, Agustina y RENDTORFF, Nicolás, «Perspectivas emergentes en el arte cerámico. Análisis de la obra de Rafa Pérez y Gregorio Peño", Boletín de Arte-UMA, n. ${ }^{4}$ 2, Departamento de Historia del Arte, Universidad de Málaga, 2021, pp. 213-223, ISSN: 0211-8483, e-ISSN: 2695-415X, DOI: http://dx.doi.org/10.24310/BoLArte.2021.vi42.11941 
dar lugar, también, a lo no humano y acercarnos a percibir sus injerencias ${ }^{1}$. En sintonía con la atmósfera de época, diversas producciones artísticas dan cuenta de cierta reorganización y redistribución de los elementos preexistentes (Alberro, 2011; Nancy, 2014), nuevas relaciones que ofrecen perspectivas alternativas de mundos (Goodman, 1990).

En un sentido similar, en los últimos años, ha crecido la revisión del arte cerámico en clave contemporánea (Leyún, 2017), como expansión de su campo (Olio, 2018), como práctica performática (Tarela, 2016), como espacio de convergencia con las ciencias (Serra, 2019), e incluso el uso de arcilla cruda (Elderton et al. , 2017). Dentro de este panorama de movimientos estructurales cobra importancia registrar las habilitaciones que se dan en el arte cerámico contemporáneo, así como las ideas que lo atraviesan y sustentan.

Los proyectos artísticos de Rafa Pérez y Gregorio Peño manifiestan notables desplazamientos respecto al modo de concebir y relacionarse con la materia determinado por el legado tradicional del arte cerámico. Nos interesa reparar en la posición de estos ceramistas dado que ya no emplean la plasticidad característica de la arcilla para imprimir formas imaginadas, sino que establecen diálogos con la materia atendiendo a las lógicas que ella propone. En lugar de controlar el proceso constructivo en su totalidad, concentran su accionar en la formulación de pastas y selección de temperaturas que activan su potencia de actuar (Latour, 2017) y revelan su capacidad para generar formas de manera autónoma (De Landa, 2013). La fuerza mineral y su potencial estético revelan una mirada que cuestiona la antigua noción que considera a la materia como yacente, velando su capacidad para interactuar con su contexto (Lucero, 2018).

En este sentido, nos proponemos analizar sus obras desde una perspectiva material. Consideraremos sus propuestas artísticas atendiendo la articulación de los siguientes aspectos: las formas que resultan de los comportamientos de la materia; los pronunciamientos de los artistas que nos permitan reconocer sus posicionamientos y los procesos constructivos de las obras. Bajo estos ejes de análisis podremos adentrarnos en aquel espesor mental y material que Siracusano (2008) propone como dimensión del hacer, donde convergen los procesos creativos, la elección de la materialidad y sus resultados.

Paralelamente, es preciso considerar la propuesta del filósofo Jean-Luc Nancy (2008) respecto a las artes. Según el autor, cada disciplina artística se diferencia de las otras por una singularidad que es construida y, a su vez, construye a las demás artes. Una íntegra relación donde nacen unas con y contra otras. Dicha perspectiva considera la colaboración equitativa de las diversas prácticas artísticas en la construcción de la noción del arte. En este sentido, detenernos en las propuestas de estos ceramistas y señalar las estrategias que construyen su singular producción, nos permitirá observar de cerca la trama del arte actual (Belinche, 2011).

\section{Un recorrido material}

Bernárdez Sanchís en su escrito Historia del arte contemporáneo y materialidad (2018) señala la desatención que ha tenido la materialidad en la Historia del Arte y advierte la necesidad de su desarrollo para aproximarnos a una visión crítica y ampliada del arte. El presente trabajo suscribe esta perspectiva de investigación como un aporte desde las especificidades del arte cerámico (Paltrinieri et al., 2015; Serra et al., 2017).

Los materiales en el arte nunca han sido considerados como en la actualidad, es por ello pertinente identificar las transformaciones sufridas a lo largo de su historia que revisaremos a continuación.

Desde la Antigüedad, en Occidente, puede identificarse una correlación entre las distintas ramas artísticas y el uso de determinados materiales. La piedra o madera pertenecían al campo de la escultura; la carbonilla y el grafito, al del dibujo y; el óleo o acrílico, al de la pintura (Eco, 2009). Cada material era concebido como un soporte donde el artista plasmaba sus ideas. En la valoración de estas obras de arte se ponderaban las habilidades técnicas y las destrezas manuales que el artista tenía para dominar los distintos materiales hasta hacerlos dóciles expresiones de sus ideas. Como expresa Bernárdez Sanchís: «La materia era así transfigurada, reconvertida, ocultada. Las recetas técnicas mostraban óptimas maneras de adiestrar a los artistas para convertir sus materias en soportes disciplinados al servicio de imágenes y formas sublimes» (2018: 22). Este modelo configuró una materialidad normativa que, supeditada a las categorías de belleza, nobleza, durabilidad y virtuosismo, pretendía sublimarla y convertirla en otra cosa.

Con el advenimiento de la modernidad, una serie de transformaciones y cuestionamientos irrumpieron este mo- 
delo. Los materiales comenzaron a colaborar en el sentido de las obras. En este proceso Bernárdez Sanchís reconoce dos fases. La primera, hacia fines del s. XIX con el surgimiento del impresionismo y la técnica del impasto: pinceladas yuxtapuestas y cargadas de materia. La sustancia dejó de ser simulada y pasó a ser mostrada como un elemento expresivo en la construcción de significado. La segunda fase surgió cuando las vanguardias artísticas de principio del s. XX comenzaron a integrar en las narrativas artísticas objetos y materiales de la vida cotidiana y de la emergente tecnología industrial. La incorporación de nuevos materiales implicó una elección consciente supeditada a sus cualidades específicas, al mismo tiempo que la mecanización de la producción industrial habilitó una repetición seriada de las imágenes cuya circulación queda desvinculada de la materialidad original (Benjamin, 1989). En el mismo período, el surgimiento de las técnicas de collages y ensamblajes aportaron a la discusión sobre la idea del artista genio ligada a la destreza manual. En muchos casos las operaciones artísticas fueron desplazadas hacia la selección, fragmentación y combinación de elementos preexistentes.

Posteriormente, en el período de posguerra se desató un proceso de experimentación artística guiado por el carácter gestual y matérico de la obra. De la mano del informalismo y el expresionismo abstracto continuó el cuestionamiento de la normatividad de la materia y los procedimientos de creación artística en los que se ve involucrada. Durante el transcurso de las décadas del sesenta y setenta, emergieron diversas corrientes artísticas que evidenciaron un desbordamiento en las fronteras disciplinares (Danto, 2009; López, 2007; Smith 2012). Con ellas devino una inédita y acelerada incorporación y tratamiento de materiales ${ }^{2}$. Sus distintas connotaciones reafirmaron su no neutralidad y destacaron su capacidad para vehiculizar significados.

En las últimas décadas, la emergencia de los nuevos materialismos filosóficos propone la restitución humana dentro del continuo de la naturaleza, y cuestiona así, su establecida preponderancia por encima de las demás formas de existencia. De este modo, proyectan reparar las relaciones entre los seres humanos y las especies no humanas (vivas y no vivas) desde una perspectiva empática y benévola centrada en lazos emocionales y materiales (Billi, 2018; Latour, 2017).

En la actualidad, diversas manifestaciones artísticas concuerdan con las coordenadas de pensamiento de esta perspectiva en donde juegan un protagonismo destacable las lógicas de otros reinos. Ejemplo de ello son algunas de las obras que participaron en la muestra Cosas extrañas. Bioarte en la Argentina ${ }^{3}$ : en Colonia ${ }^{4}$, una bio-instalación sonora de Gabriel Sacco, la actividad de un conjunto de bacterias genera patrones rítmicos que se proyectan de manera amplificada en el espacio. Proyecto Biosferas ${ }^{5}$, instalación de Joaquín Fargas, una serie de esferas de acrílico selladas herméticamente disponían en su interior ecosistemas vegetales inmersos parcialmente en agua. Con el transcurrir del tiempo, la temperatura y luminosidad del ambiente incidieron en el estado del agua y en el desarrollo de plantas y bacterias. Morfogénesis $s / z^{6}$, de Agustín Bucari presenta un repollo colorado embebido en una solución de alumbre potásico que genera cristales minerales. Durante el transcurso de la exposición los cristales se desarrollaron, crecieron y se propagaron aleatoriamente sobre la superficie del vegetal. En los ejemplos mencionados las lógicas de cada reino (monera, vegetal y mineral respectivamente) cobran un notorio protagonismo al participar como co-creadores de las obras.

En particular, al momento de analizar obras en las que juega un rol fundamental el reino mineral, es importante actualizar y refinar nuestro sensorium, es decir, poner el foco en las reacciones y comportamientos que desata la materia de modo que podamos percibir su capacidad de conmoción (lovino \& Oppermann, 2018). En este sentido, asumimos la postura de los nuevos materialismos en torno a la redistribución de la capacidad de accionar, antes relegada solo a lo vivo y, principalmente, a lo humano. En palabras de Manuel De Landa:

Una filosofía que pretende reemplazar las visiones esencialistas de la génesis de la forma (que implican una concepción de la materia como receptáculo inerte de formas exteriores) por otra donde la materia esté de antemano preñada de capacidades morfogenéticas, de tal manera que sea capaz de generar una forma por cuenta propia (2013: 34-35).

Atender esta propuesta invita a repensar el modo en que consideramos, imaginamos y, sobre todo, cómo nos relacionamos con la materia y, para ello, es preciso arribar a un análisis que contemple tanto su capacidad morfogenética (De Landa, 2013) como su potencia de actuar (Latour, 2017). Este último concepto parte de la idea de que en el 
mundo material las consecuencias ya están en la causa, por ende, las formas que pueda llegar a tomar el mundo material responden a su contingencia. Así Latour resalta que la fuerza de la naturaleza es lo contrario a un actor inerte: la materia retroactuaría sobre aquello que se le hace con una potencia capaz de imponerse ante las fuerzas humanas, "es evidente que no hay que simplificar de antemano el reparto de posibilidades de actuar entre actores llamados humanos y no humanos» (Latour, 2017: 81).

Las obras cerámicas que vibran en esta frecuencia requieren nuevos ejes de análisis que atiendan a sus lógicas y comportamientos, es decir, que consideren aquellos términos específicamente matéricos como fluidez, transformación, interacción, interferencia, tensión, viscosidad, entropía, entre otros (Bernárdez, 2018). La destreza técnica del modelado del artista se ve eclipsada por la vitalidad de las formas y movimientos generados por la materia, haciendo estallar la idea de sustancia inactiva. La materialidad de la obra deviene campo de encuentro en el que se realizan mutuamente las agencias humanas y no humanas, ya no bajo el dualismo opresivo que distingue entre las mentes activas y la naturaleza inerte, sino desde una mirada posthumana (lovino \& Oppermann, 2018).

\section{Apuntes ceramistas \\ Hacia nuevas sensibilidades matéricas}

Son muchos los ceramistas que mantienen vigente milenarias operaciones al momento de construir sus piezas. Entre ellas se destacan el modelado y el horneado, como estrategias para diseñar y conservar -respectivamente- las formas ideadas por el ceramista. Ambos procedimientos se han erigido como pilares del arte cerámico. Sin embargo, en los últimos años han aflorado operaciones alternativas que ponen en cuestión la jerarquía tanto del modelado como único medio para conformar las piezas, como del horneado como el procedimiento mediante el cual se petrifican esas formas construidas. En lugar de continuar por estas sendas, los ceramistas que a continuación analizaremos, se detienen en la generación de condiciones para que la materia actúe: exploran formulaciones de pastas que luego exponen a temperaturas extremas que logren conmoverla.

El reconocido artista español Rafa Pérez ${ }^{7}$ presenta una prolífica obra cerámica en la que se observan los des- plazamientos que intentamos delinear. En el criterio con el que valora sus obras podemos leer su desapego respecto a aquella idea sobre el artista como creador único: «Considero que mis trabajos son buenos cuando abro el horno y, al no reconocer las piezas como mías, me sorprenden. Con este proceso acumulo en mi estudio cientos de pruebas y objetos que llenan pisos y escaleras» ${ }^{8}$. Sus palabras nos ofrecen también una imagen del taller, del laboratorio de ideas (Siracusano, 2008). Un espacio colmado de objetos cerámicos que resultan de sus exploraciones. El proceso creativo se vuelca hacia una experimentación matérica intensa y metódica, una curiosidad por las reacciones que se desatan durante los procesos térmicos. La manipulación minuciosa de minerales y su combinación en formulaciones precisas dejan entrever una diagramación que provoca ciertas consecuencias tras la cocción.

Al observar su producción, resulta llamativa la recurrencia de obras sin título. En este gesto podemos reconocer la pertenencia de cada pieza al proyecto exploratorio más amplio que le da origen, sin necesidad alguna de distinción respecto a aquellas pruebas que habitan su taller. De esta manera, se refuerza el carácter ensayístico y abierto resultado de un diálogo permanente y sostenido con la materialidad cerámica, diálogo del que cada pieza constituye, en última instancia, un registro de su contingencia.

La singularidad de cada pieza surge como resultado de sutiles movimientos en las diagramaciones previas que realiza el ceramista, la composición de cada pasta repercute luego en las formas, colores, calidades de superficies y texturas, es decir, en el carácter cerámico que se desarrolla en cada oportunidad. Una intención humana que permanece latente en el objeto cerámico. A las numerosas reacciones provocadas por el horno podemos sumarle la que se imprime en el campo afectivo del ceramista. Observemos en sus propias palabras cómo la morfogénesis resuena en su emocionalidad: "Estoy enamorado de la arcilla, por eso trabajo con ella, porque es un material que tiene muchas posibilidades, como también el fuego que lo cambia todo» (R. Pérez, conversación personal, 11 de mayo de 2019). La atracción que siente por las reacciones y formas contingentes de la materia lo han llevado a sostener en el tiempo una seria exploración, la cual, le ha permitido desarrollar distintas pastas con formulaciones específicas que derivaron en una secuencia de combinaciones entre ellas muy caracte- 


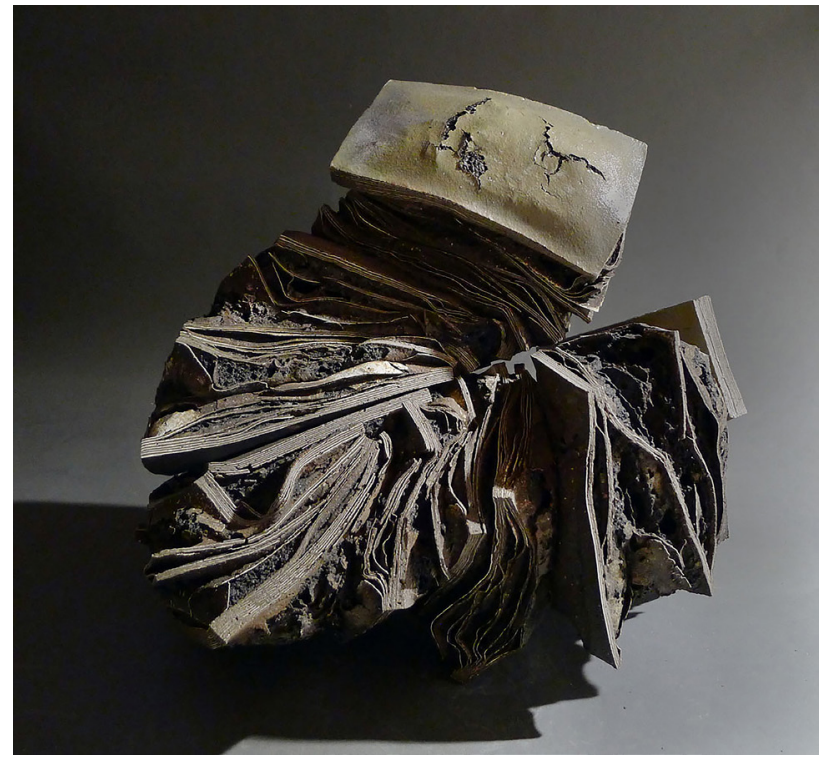

1. Rafa Pérez. Sin título. 2018. Barro rojo, pasta personal, tierra sigillata horneada a $1150^{\circ} \mathrm{C}$. Técnica: superposición de láminas. Medidas aproximadas: $40 \times 35 \times 38 \mathrm{~cm}$

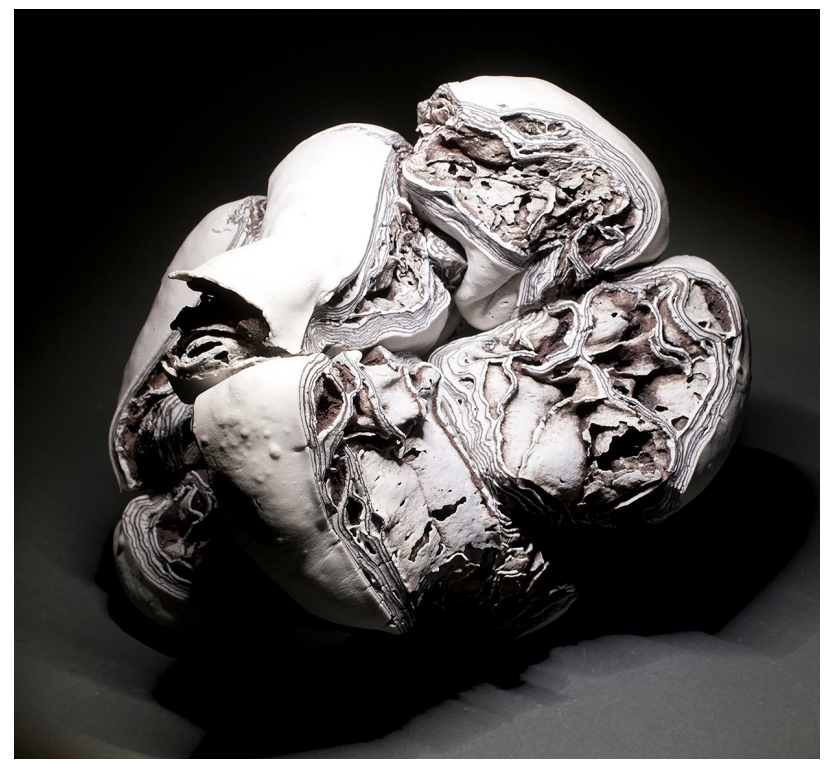

2. Rafa Pérez. Sin título. 2015. Porcelana baja, pasta personal, horneadas a $1180^{\circ} \mathrm{C}$. Técnica: superposición de láminas. Medidas aproximadas: $37 \times 27 \times 20 \mathrm{~cm}$ rística y un procedimiento de trabajo con el que se identifica su producción. Elabora pastas personales con distintas formulaciones, a una la denomina falsa porcelana y, a la otra, expansiva de acuerdo a las propiedades de cada una. Con ambas pastas realiza láminas que luego apila de manera alternada. Repite este proceso de conformación hasta obtener un bloque cuyo interior está conformado por un cuerpo de estratos delgados de pastas intercaladas. Las piezas que construye con estas planchas dan cuenta de un devenir matérico activado durante los procesos térmicos [1] y [2]. La expansión de una y contención de otra -dos fuerzas en sentidos contrarios con intensidades desiguales-, provocan una serie de reacciones y movimientos en los que se configura un paisaje mineral de fuerza propia, que contiene y petrifica las tensiones ocurridas en su interior.

En la figura [3] y [4] vemos la incorporación de un hilo metálico que rodea la pieza e interviene en su expansión. Podemos hablar de un modelado térmico para referir a estos procesos de ebullición, liberación de gases, multiplicación del tamaño, reacomodamiento de las partículas, empuje, compresión, deformación, desgarro, agrietamiento y demás reacciones surgidas por la potencia de actuar de la cerámica durante su exposición a temperaturas extremas.
Así, su propuesta artística impulsada por la pasión y entusiasmo que le despierta la interacción con la cerámica, se sostiene en la continua búsqueda y exploración de formas, texturas y comportamientos que pueda expresar la materia, incluyendo materiales no cerámicos que aportan sus propias características.

El segundo caso de estudio es la producción del español Gregorio Peño ${ }^{9}$. Proveniente de una familia alfarera, se presenta como la quinta generación de ceramistas, heredero de una serie de saberes, conocimientos, modos de hacer y demás tradiciones que formaron parte de su crianza:

Los procesos que conforman la cerámica desde que se recoge la tierra, se prepara la arcilla, se crea el objeto y se somete al fuego, marcan una línea temporal que me es familiar. La transformación del material es para mí un diccionario conceptual que delimita un itinerario artístico al margen de lo fijado por escuelas y grupos ${ }^{10}$.

Observemos que su posición ante esta herencia ceramista no se da en términos estáticos dirigidos a la conservación de un legado o, como menciona en la cita, adhesión a una escuela o tendencia determinada, sino que muestra una 


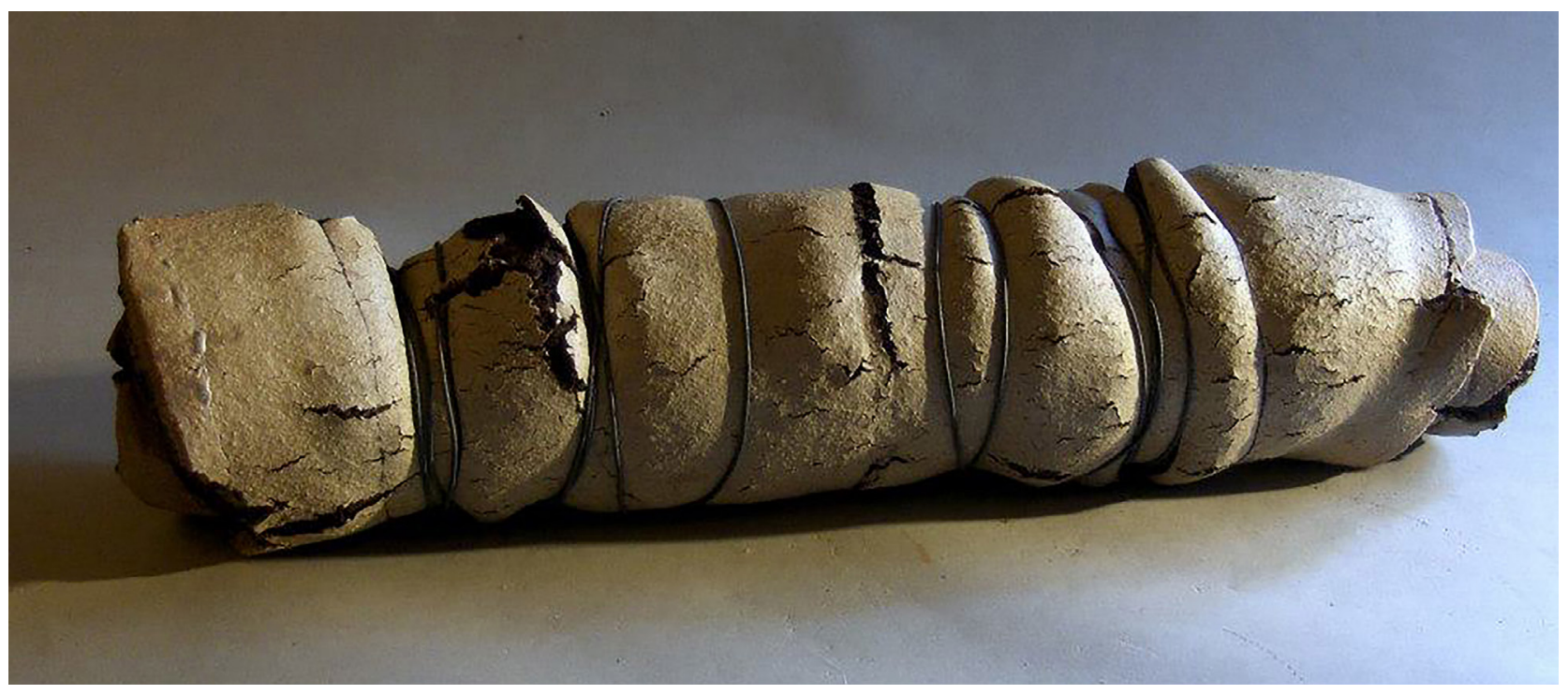

3. Rafa Pérez. Sin título. 2003. Pastas personales y alambre, horneada a $1150^{\circ} \mathrm{C}$. Técnica: superposición de láminas. Medidas aproximadas: $60 \times 14 \times 14 \mathrm{~cm}$

preocupación por actualizar el hacer cerámico poniendo el foco en las transformaciones y gestos que expresa el material, con los que se propone elaborar un lenguaje específico («diccionario conceptual»).

En este sentido, vemos cómo los fenómenos tales como la plasticidad de la pasta, su expansión y la fuerza de

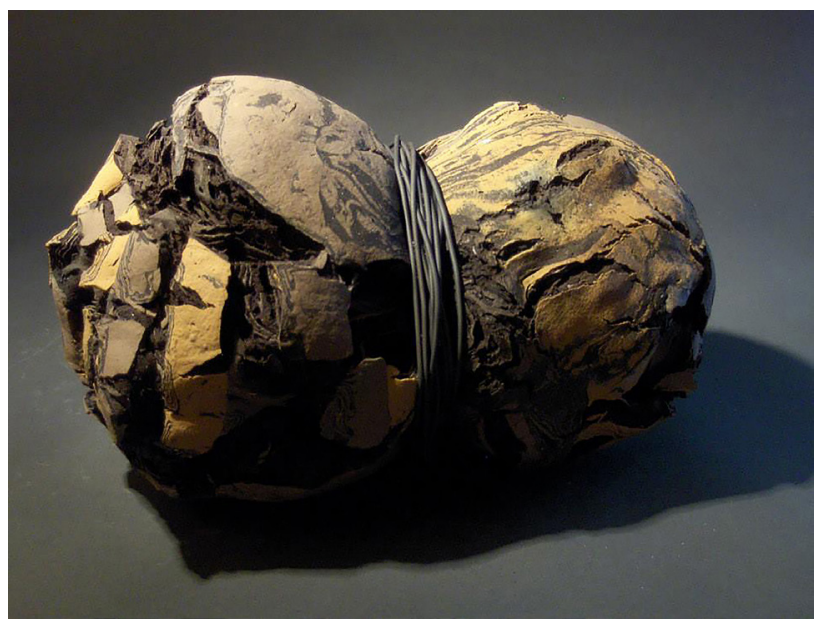

4. Rafa Pérez. Sin título. 2012. Porcelanas coloreadas, pasta personal y alambre; horneada a $1180^{\circ} \mathrm{C}$. Técnica: superposición de láminas. Medidas aproximadas: $40 \times 20 \times 20 \mathrm{~cm}$ gravedad, juegan un rol importante en sus proyectos artísticos. Rasgos que el artista refuerza al denominar sus series con referencia a comportamientos, transformaciones o cualidades matéricas: Surcos (2011); Floraciones (2011-2013), Formas Abatidas (2014) Compresiones (2017), Colapso (2020). Se puede reconocer en este aspecto una fuerte pulsión por desdibujar la figura de artista-creador-único y hacer de la hibridez creativa un nodo central de su proyecto artístico:

\begin{abstract}
Hay un gesto común en toda mi investigación objetual, un gesto que no es simplemente una mediación entre lo humano y las cosas, sino un ensamblaje, un cruce de trayectorias que permite que la arcilla forme parte activa de la creación, sin líneas divisorias entre práctica y teoría o artesano y artista. La materia concebida como elemento de profundización y desarrollo ${ }^{11}$.
\end{abstract}

La combinación de dos elementos que históricamente fueron organizados como dualidades enfrentadas (teoría y práctica o artesano y artista) encuentra de alguna manera un correlato visual en sus piezas, y es desde la materialidad que construye estrategias para su desarrollo. Por ejemplo, en la serie Floraciones [5] y [6] se observa una articulación entre 


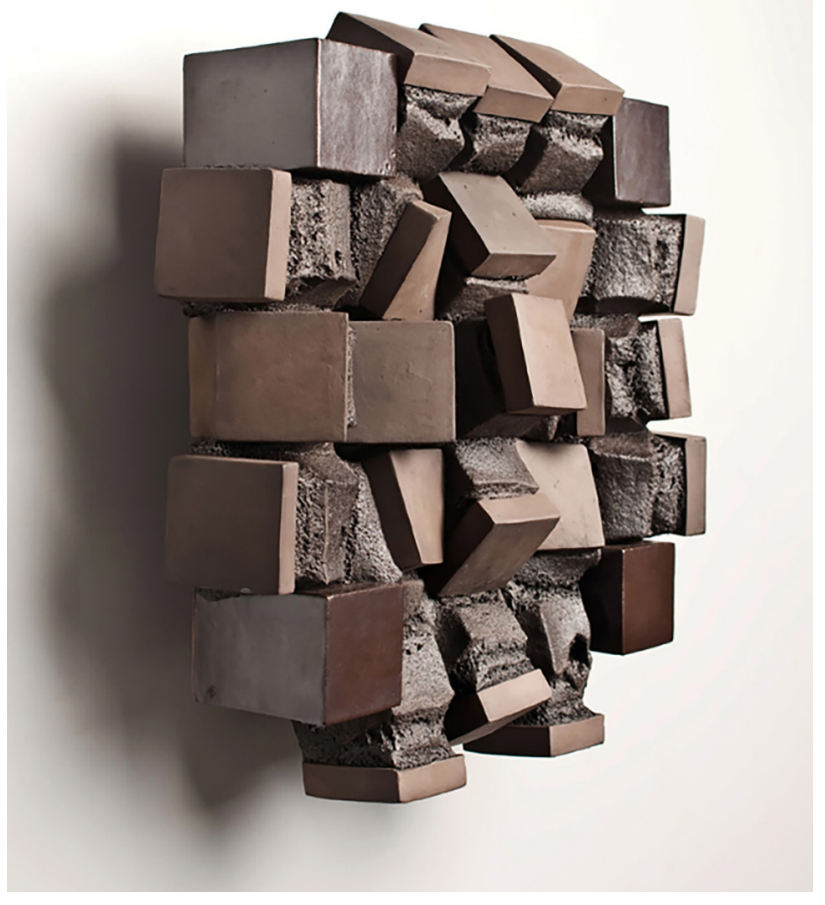

5. Gregorio Peño. Floración I. 2011. Sobrecocción de pastas cerámicas, horneadas a $1100^{\circ} \mathrm{C}$. Técnica mixta. Medidas aproximadas: $32 \times 32 \times 12 \mathrm{~cm}$

lo geométrico y lo amorfo, los vértices definidos, bordes filosos y planos rectos se ven empujados y redireccionados por un material cerámico que crece y se expande, que imprime una fuerza caótica a una serie de formas ordenadas. En esta obra que encuentra la metáfora de floración para nombrar el ensamblaje de lo rígido con lo blando, aparece otra figura retórica que profundiza la intención del proyecto: la repetición. De manera ordenada cada uno de estos cubos-no cúbicos se yuxtaponen organizando el cuerpo de la pieza escultórica. La repetición viene a evidenciar que cada encuentro combinatorio es singular y azaroso (algunos más abiertos, otros estirados, desplomados hacia los costados, expandidos o retenidos) y, al mismo tiempo, refuerza cierta regularidad que finalmente construyen estos cuerpos en conjunto, porque es la potencia de actuar de estas dos pastas empleadas la que determina la contingencia de estas piezas.

En la serie Formas abatidas [7] y [8] procede con una metodología similar en cuanto a la combinación de pastas diferentes, esta vez enfatizando la incidencia de la fuerza de

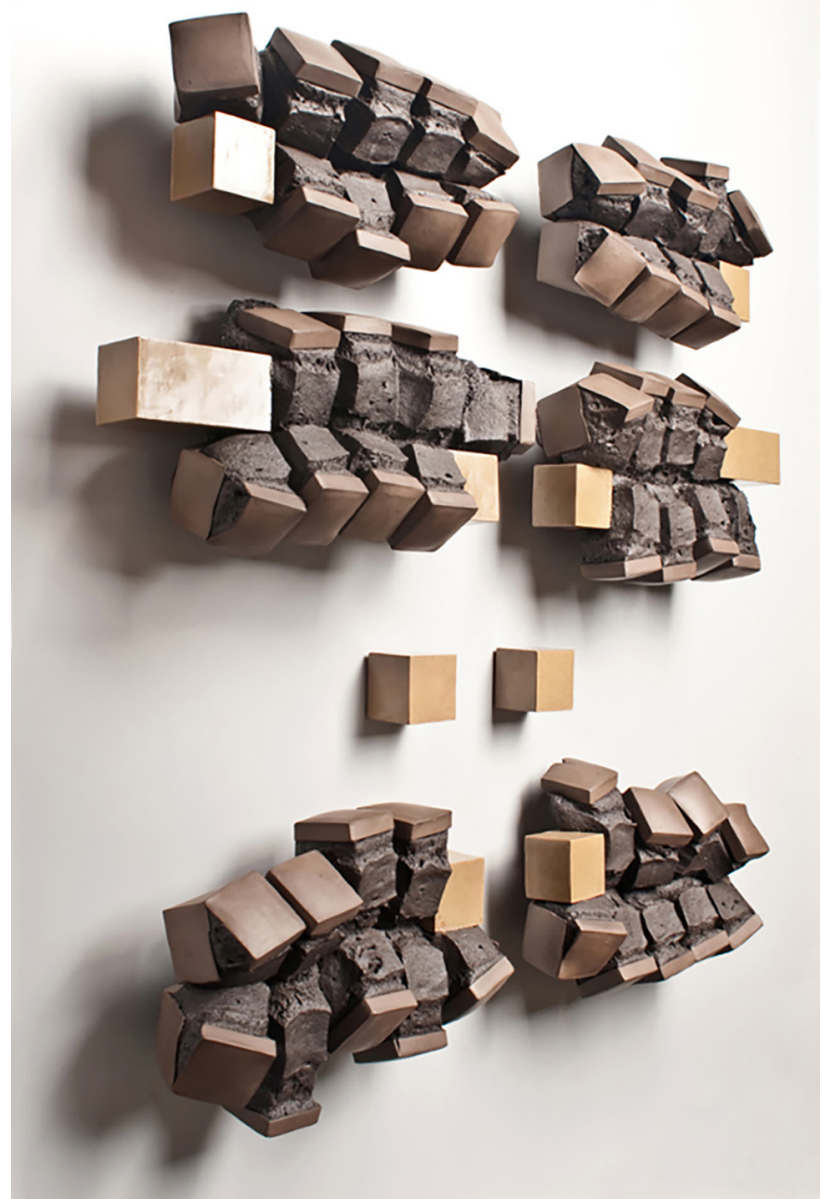

6. Gregorio Peño. Floración XV. 2013. Sobrecocción de pastas cerámicas horneadas a $1100^{\circ} \mathrm{C}$. Técnica mixta. Medidas aproximadas: $67 \times 66 \times 11 \mathrm{~cm}$

gravedad. Para ello construye piezas verticales con una pasta que a altas temperaturas se ablanda y otra que mantiene su forma prácticamente inalterada. La morfogénesis de este cuerpo colapsado manifiesta la impronta del peso de una sobre la otra, desarrollando pliegues, arrugas, grietas, inclinaciones y demás características específicas. Observamos también que la superficie de una y otra pasta no solo contrastan por su estructura blanda o rígida, por su color, sino también se enfatiza la diferencia por una textura porosa-mate y otra tersa-brillante, de una pasta coloreada y una esmaltada, respectivamente (G. Peño, conversación personal, 29 de julio de 2019). 


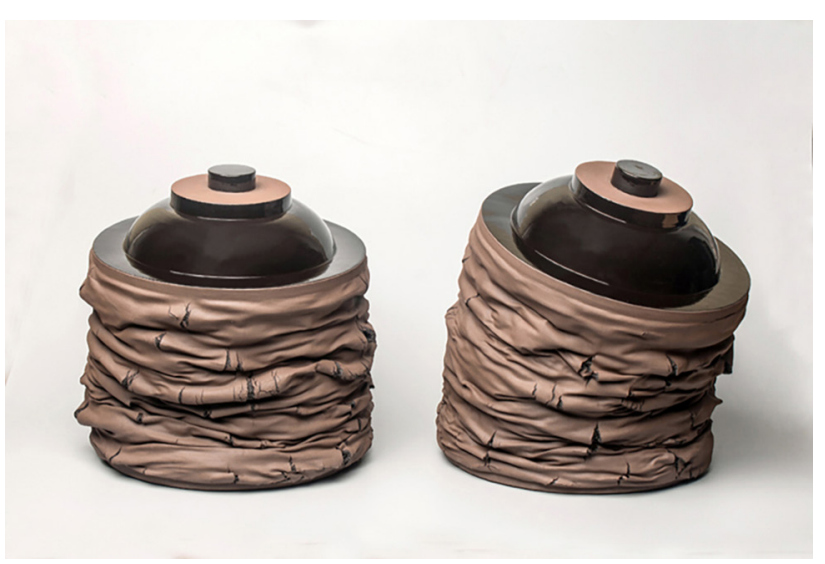

7. Gregorio Peño. Formas abatidas XXIV. 2014. Sobrecocción de pastas cerámicas horneadas a $1100^{\circ} \mathrm{C}$. Técnica mixta. Medidas aproximadas: $33 \times 33 \times 34$ y $35 \times 32 \times 36 \mathrm{~cm}$

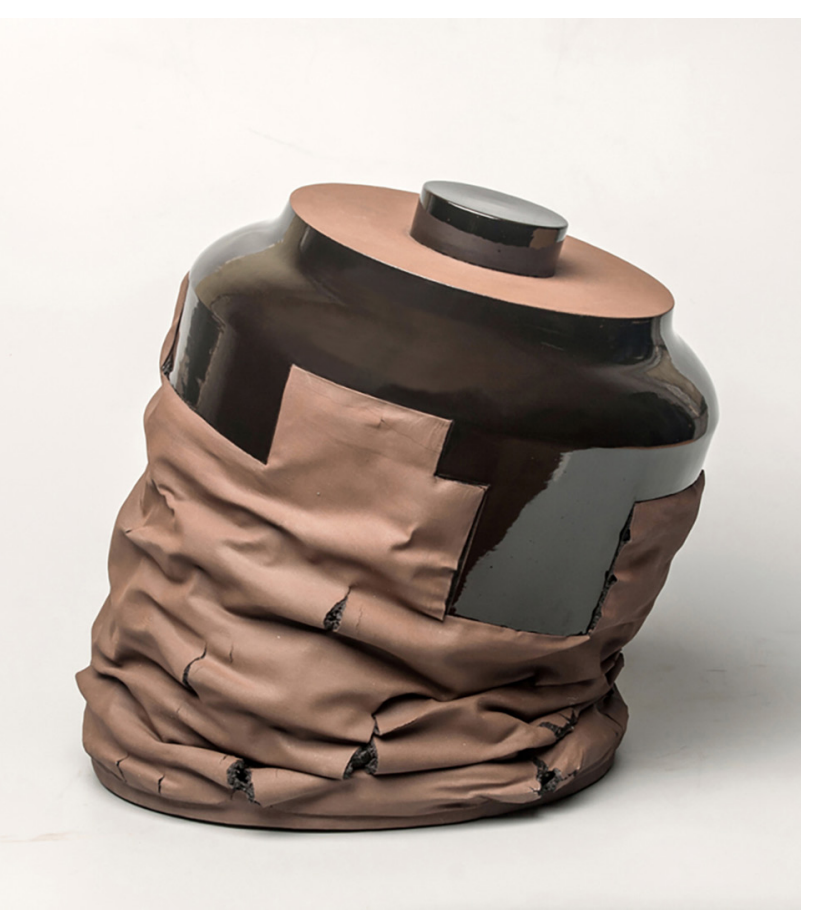

8. Gregorio Peño. Formas abatidas XXIII. 2014. Sobrecocción de pastas cerámicas horneadas a $1100^{\circ} \mathrm{C}$. Técnica mixta. Medidas aproximadas: $32 \times 32 \times 36 \mathrm{~cm}$
Estas esculturas mantienen un equilibrio preciso entre el peso ejercido, la viscosidad de la pasta que se ablanda, los espesores de cada parte, las temperaturas de cocción y los tiempos de exposición a esas temperaturas, por mencionar algunas variables en juego. La elaboración de estos contextos diseñados en función de las materialidades da cuenta del cúmulo de investigaciones empíricas basadas en las reacciones y comportamientos de la materia que antecede a cada escultura. En ellas se conforma el diccionario conceptual que sustenta su poética visual.

\section{Una mirada renovada de la cerámica Servir de voz a la materia}

Al fin y al cabo, es de lo que se trata: un diálogo entre la materia y el artista

Peño, 2016

El recorrido que hemos trazado hasta aquí nos acerca a una forma de cerámica contemporánea que presenta una particular concepción de la materialidad y de su rol en el arte. La articulación entre el análisis formal de las piezas, sus procesos constructivos y algunas reflexiones de los ceramistas, nos permite extraer de su entramado algunas claves respecto a cómo se posiciona el artista con la materialidad. De este análisis se desprende que en la obra de Rafa Pérez y Gregorio Peño los nuevos materialismos se proyectan en la relación empática que entablan con la materialidad (Rainieri, 2015), a través de la cual se diluye la idea del artista cómo único creador. La creación de la obra se expande a una instancia que ya no es exclusiva de lo humano. Estas piezas arrojan la pregunta sobre quién o qué actúa, quién o qué acciona, quién o qué determina las formas escultóricas.

Presenciamos una producción artística que comparte, dialoga, se mezcla, indaga, observa, se conmueve por otras lógicas de existencia, en este caso, por las lógicas minerales. Esta confluencia cuestiona la escisión entre lo humano y lo no humano para poner en evidencia sus hibridaciones y definición mutua, una configuración co-operativa propia de una mirada posthumanista (lovino \& Opperman, 2018). E arte cerámico se muestra ahora permeable a determinadas corrientes actuales y expresa su afinidad con algunas coordenadas que proponen los nuevos materialismos. 
Con todo ello podemos asumir la presencia de una práctica que revisa el oficio cerámico y propone una reactualización que rescata la fuerza del accionar matérico y delinea con ella una estética mineral (Lucero, 2018). En el presente trabajo, hemos referido tan solo cómo se manifiesta en dos ceramistas consagrados por su trayectoria, pero sería interesante ampliar este análisis al extenso campo de producción de arte cerámico actual para reconocer las múltiples expresiones de esta estética mineral y la profundidad de sus posibilidades.

Emerge un arte cerámico que desplaza el peso gravitacional antes puesto en el modelado de la pasta hacia vías alternativas de producción en la que surge un nuevo tipo de modelado: se modela la composición de las pastas y se modelan los contextos térmicos de transformación quí- mica. En otras palabras, hay un mayor detenimiento tanto en el diseño de la formulación de pastas (considerando variaciones en su composición) como en la diagramación de los procesos de cocción (atendiendo a las reacciones específicas de cada material). Todo ello exige un conocimiento minucioso de las propiedades de cada componente, la decodificación de las lógicas minerales, el ensayo, prueba, exploración, observación, registro e indagación de una materia que ya no puede pensarse inerte. En este sentido, el ceramista entabla un diálogo sostenido con los materiales, ajusta y perfecciona las preguntas que le formula, genera condiciones para que despliegue sus respuestas, se deja atravesar por la potencia de actuar de la materia y asume la existencia de un universo desconocido de infinitas posibilidades empíricas.

\section{Notas}

1 Estos esquemas son actualmente revisados desde diversas disciplinas. En el presente trabajo recogemos algunas ideas enraizadas en los nuevos materialismos provenientes de la filosofía (Latour, 2017; de Landa, 2013; Billi, 2018; Lucero, 2018; Ludueña, 2012; Braidotti, 2015); del feminismo (Cano, 2015), de estudios ecológicos (lovino \& Operman) y su emergente en prácticas artísticas (Bernárdez, 2018; Lucero, 2020; Rainieri, 2015).

2 Pensemos, por ejemplo, en el arte Povera y el uso de materiales pobres; el Land Art y la incorporación de materiales de la naturaleza; el Minimalismo con materiales procedentes de las industrias o el Conceptualismo que planteó la desmaterialización de la obra de arte (Ferrer, 2010).

3 Muestra realizada en el Centro de Arte de la Universidad Nacional de La Plata (abril, 2019). Curada por la Dra. Natalia Mateweky (Argentina; La Plata) y el Dr. Daniel López del Rincón (España, Barcelona). Más información en: <Cosas extrañas. Bioarte en la Argentina-Centro de Arte (unlp.edu.ar)> (fecha de consulta: 16-06-2021).

4 «Colonia». En: <Colonia (dariosacco.com.ar)> (fecha de consulta: 16-06-2021).

5 «Proyetco biósfera». En: <Proyecto Biosfera | Joaquín Fargas - Artista (joaquinfargas.com)> (fecha de consulta: 16-06-2021).

6 "Morfogénesis s/Z». En: <www.instagram.com/agustin.bucari> (fecha de consulta: 16-06-2021).

7 Nació en 1957 en Haro, La Rioja, España. Estudió cerámica en la Escuela Massana de Barcelona. En 2007 fue elegido Miembro de la Academia Internacional de Cerámica. Cuenta con más de cien exposiciones (colectivas e individuales) y ha ganado numerosos y relevantes premios. Su producción ha sido motivo de publicaciones en artículos y libros de arte cerámico. Información detallada en: <www.rafaperez.es> (fecha de consulta: 16-06-2021).

8 «Declaración del artista». En: <About (rafaperez.es)> (fecha de consulta: 16-06-2021).

9 Nació en 1983, en Toledo, España. Estudió Artes Plásticas y Diseño en Cerámica Artística en Madrid. Su obra ha sido reconocida dentro y fuera de España con diferentes premios y bienales. Asimismo, forma parte de colecciones públicas. Más información en: <Bio - Gregorio Peño (gregoriopeno.com)> (fecha de consulta: 16-06-2021).

10 «Statement». En: <Statement - Gregorio Peño (gregoriopeno.com)> (fecha de consulta: 16-06-2021).

11 «Statement». En: <Statement - Gregorio Peño (gregoriopeno.com)> (fecha de consulta: 16-06-2021).

\section{Bibliografía}

BENJAMIN, Walter (1935), «La obra de arte en la era de la reproductibilidad técnica», en Discursos Interrumpidos I, Taurus, Buenos Aires, 1989. ALBERRO, Alexander (2011), «Periodizar el arte contemporáneo». En ¿Qué es el arte contemporáneo hoy?, Simposio Internacional, Universidad Pública de Navarra, Pamplona, pp. 153-169.

BELINCHE, Daniel (2011), Arte, poética y educación, El autor, La Plata.

BERNÁRDEZ SANCHÍS, Carmen (2018), «Historia del arte contemporáneo y materialidad», en MOLINA, Álvaro (ed.), Historia del arte en España, Editorial Polifemo, Madrid, pp. 219-271. 
BRAIDOTTI, Rosi (2015), Lo Posthumano, Trad. J. C. Gentile Vitale, Gedisa, Barcelona.

BILLI, Noelia (2018), «La naturaleza y la estética filosófica. El pensamiento de la naturaleza en el materialismo posthumano», Dois pontos, vol. 15, n. $^{\circ} 2$, noviembre, pp. 99-106.

CIRLOT, Lourdes (1993), Primeras vanguardias artísticas, Editorial Labor, Barcelona.

DANTO, Arthur C. (2009), «Introducción: moderno, posmoderno y contemporáneo», en Después del fin del arte: el arte contemporáneo y el linde de la historia, Paidós, Buenos Aires, pp. 25-41.

DE LANDA, Manuel (2013), «Deleuze, los diagramas y la génesis de la forma», trad. I. Semo Bechet, Fractal, vol. 18, n. 69, pp. 33-50.

ELDERTON, Louisa, MORRILL, Rebecca y LILLEY, Clare (2017), Vitamin C: Clay + Cerámic in the Contemporary Art, Phaidon Press, Londres. FERRER, Mathilde (2010), Grupos, movimientos y tendencias del arte contemporáneo desde 1945, trad. M. Malfé, La Marca Editora, Buenos Aires.

GOODMAN, Nelson (1990), Maneras de hacer mundos, trad. C. Thiebaut, La Balsa de la Medusa, Madrid.

IOVINO, Serenella \& OPPERMANN, Serpil (2018), «Ecocrítica Material: Materialidad, agencia y modelos narrativos», trad. N. Billi y G. Lucero, Pensamiento de los confines, n. ${ }^{\circ} 31-32$, pp. 215-227.

LATOUR, Bruno (2017), "Como no (des)animar la naturaleza», En Cara a cara con la naturaleza. Una nueva mirada sobre el cambio climático alejada de las posiciones apocalípticas, trad. A. Dilon, Ed. Siglo veintiuno, Buenos Aires, pp. 57- 92.

LEYÚN, Maite (2017), Estudio de los usos de la cerámica en las prácticas artísticas contemporáneas (tesis doctoral), director: GARRAZA Ángel, co-directora: LAUZIRIKA Arantza, Departamento de Escultura Facultad de Bellas Artes, UPV/EHU, España.

LÓPEZ ANAYA, Jorge (2007), El extravío de los límites. Claves para el arte contemporáneo, Emecé, Buenos Aires.

LUCERO, Guadalupe (2018), «Cristal y Piedra. Para una estética mineral», Pensamiento de los confines, vol. 31, Guadalquivir, Buenos Aires, pp. 250-255.

LUCERO, Guadalupe (2020), «Performatividad material y expresividad mineral», Artefilosofia, vol. 15, pp. 350-361. En: <https://periodicos. ufop.br/raf/article/view/4304/3588> (fecha de consulta: 16-06-2021).

LUDUEÑA ROMANDINI, Fabian (2012), Más allá del principio antrópico: hacia una filosofía del outside, Prometeo Libros, Buenos Aires.

NANCY, Jean-Luc (2008), "Las artes se hacen unas contra otras», Las musas. Trad. H. Pons. Amarrortu, Buenos Aires, pp. $135-146$.

NANCY, Jean-Luc (2014), «Prólogo: actualidad del arte» y «El arte hoy», en El arte hoy, trad. C. Pérez López y D. Álvaro, Prometeo Libros, Buenos Aires, pp. 9-36.

OLIO, Graciela, TORO, Claudia y ALONSO, Anabel (2018), «La relación barro-cuerpo-espacio. Una propuesta pedagógica experimental en el campo de la cerámica expandida», Nupeart, vol. 18, pp. 14-27. https://doi.org/10.5965/2358092518182017014.

PALTRINIERI, Agustina, SERRA, Florencia, RENDTORFF, Nicolás y MELO, Florencia (2015), «Tecnología milenaria en cuatro microrrelatos: pastas coloreadas en la cerámica contemporánea», en X Jornadas Nacionales de Investigación en Arte en Argentina y América Latina (La Plata, 2015). En: <http://sedici.unlp.edu.ar/handle/10915/60827> (fecha de consulta: 16-06-2021).

PEÑO, Gregorio, «BIO». En: <http://gregoriopeno.com/> (fecha de consulta: 16-06-2021).

PÉREZ, Rafa, «Main page». En: <Main Page (rafaperez.es)> (fecha de consulta: 16-06-2021).

RAINIERI, Marco (2015), «Poéticas de los materiales en los procesos de vinculación empática. Significados y significantes de los materiales en la indagación artística sobre la relación cultura/naturaleza en el contexto de la crisis ecológica sistémica global», Ecozon@, vol. 6, n. ${ }^{\circ}$ 2, pp. 26-37. https://doi.org/10.37536/ECOZONA.2015.6.2.663.

SERRA, Florencia (2019), Materialidad en el arte cerámico contemporáneo. Una zona de convergencias con la práctica científica (tesis doctoral), directora: DILLON, Verónica, co-director: RENDTORFF, Nicolás, Departamento de Plástica, Facultad de Artes, Universidad Nacional de La Plata, Argentina.

SERRA, Florencia, PALTRINIERI, Agustina y RENDTORFF, Nicolás (2017), «La ciencia y el arte cerámico. Confluencia en la obra de Graciela Olio", Metal, vol. 3, pp. 50-57. En: <http://papelcosido.fba.unlp.edu.ar/ojs/index.php/metal/article/view/459> (fecha de consulta: 16-06-2021).

SIRACUSANO Gabriela (2008), Las entrañas del arte: un relato material (s. XVII-XXI), Del 16 de septiembre al 28 de octubre de 2008 [Muestra colectiva], Buenos Aires, Fundación OSDE: Imago Espacio de Arte. 
SMITH, Terry (2012), «¿Qué es el arte contemporáneo?», en ¿Qué es el arte contemporáneo?, trad. H. Salas, Siglo veintiuno, Buenos Aires, pp. 299-336.

TARELA Mariel (2016), «Variaciones en la práctica artística de la cerámica contemporánea en las primeras décadas del siglo XXI y sus repercusiones en la práctica docente», en VIII Jornadas de Investigación en Disciplinas Artísticas y Proyectuales (La Plata, 6 y 7 de octubre de 2016). En: <http://sedici.unlp.edu.ar/handle/10915/56003> (fecha de consulta: 16-06-2021).

TITI RECORDS (2016), Gregorio Peño. El lenguaje de la materia [video]. En: <https://www.youtube.com/watch?v=hQgXUp55cy4> (fecha de consulta: 16-06-2021). 